\title{
Erciyes Yöresi Titrek Kavak Meşcerelerinde İlk Aralama Bakımlarının Ekonomik Analizi
}

\author{
Ali Osman GÜZEL ${ }^{1}$, İsmet DAŞDEMİR ${ }^{2 *}$ \\ ${ }^{1}$ İç Anadolu Ormancılık Araştırma Enstitüsü Müdürlüğü, 06530, ANKARA \\ ${ }^{2}$ Bartın Üniversitesi Orman Fakültesi, Orman Mühendisliği Bölümü, 74100, BARTIN
}

\section{Öz}

Erciyes yöresinde saf, doğal, tek tabakalı, hiç bakım görmemiş, sıklık çağını henüz geçmiş ve ilk aralama çağına ulaşmış yaklaşı 1.468 ha titrek kavak (Populus tiremula L.) meşceresi bulunmaktadır. Bu meșcerelerin silvikültürel açıdan bakıma ihtiyacı vardır. Yapılacak ilk aralama çalışmalarının ekonomik olup olmadığının araştırılması ve işletme ekonomisi bakımından incelenmesi önem arz etmektedir. Bu çalışma, Erciyes yöresindeki titrek kavak meşcerelerine yapılacak ilk aralama müdahalelerini odun üretimi açısından incelemek ve ekonomisini ortaya koymak amacıyla ele alınmıştır. Çalışmada 2017 yılı fiyatları esas alınarak maliyet ve gelir hesapları yapılmıştır. Yapılan müdahalelerde üretilecek ürünlerin maliyet bedeli $(\mathrm{MAB})=(\mathrm{TB}+\mathrm{FG}+\mathrm{DG}+\mathrm{SG})$ x 1,0M formülüyle hesaplanmıştır. Orman Genel Müdürlüğünün $1 \mathrm{~m}^{3}$ lif-yonga kavak odunu için üretim taban fiyatları baz alınarak, farklı uzaklıktaki örnek alanlardaki meşcerelerden elde edilen ürün çeşitlerinin miktarları ve muhammen satış fiyatları belirlenerek gelir tahminleri yapılmıştır. Bilahare gelir ve maliyet karşılaştırılmaları yapılarak titrek kavak meşcerelerine yapılan müdahalelerin ekonomisi ortaya konulmuştur. Araştırma sonunda ilk aralama bakımlarından elde edilecek emvalin lif yonga odunu niteliğinde olduğu, $1 \mathrm{~m}^{3}$ odunun yaklaşık 35 TL bedelle dikili ağaç halinde satıldığı, örnek alanlarda damgalanan toplam 4.370 adet ağacın hacminin 272,83 $\mathrm{m}^{3}$ olduğu ve orman işletmesinin bu üretimden toplam 9.549,05 TL net gelir elde ettiğ saptanmıştır. Bu sonuçlara göre Erciyes yöresindeki hiç bakım görmemiş, sıklık çağını henüz geçmiş ve ilk aralama çağına ulaşmış titrek kavak meşcerelerine aralama müdahalelerinin yapılmasının ve odun üretiminin işletme ekonomisi bakımından uygun olduğu ve işletmeye ekonomik bir getiri sağladığı ortaya konmuştur. Ayrıca yapılacak üretim, orman ürünleri sanayinin hammadde ihtiyacının karşılanmasına, odun arz açığının kapatılmasına, istihdam, katma değer yaratılmasına ve böylece ülke ekonomisinin katkı sağlayacaktır.

Anahtar Kelimeler: Odun üretimi, Titrek kavak, Maliyet bedeli, Dikili ağaç satış fiyatı, Erciyes Dağı.

\section{Economic Analysis of the First Interval Maintenances in Trembling Poplar Stands in the Erciyes Region}

\begin{abstract}
In the Erciyes region, there are about 1,468 ha trembling poplar (Populus tiremula L.) stands that are pure, natural, single-layer, never maintained and have just passed the age of frequency and reached the first interval age. These stands need silvicultural maintenance. It is important to investigate whether the first interval maintenances are economical and examine them in terms of business economy. This study was handled in order to examine the first interval maintenances on the trembling poplar stands in the Erciyes region in terms of wood production and to reveal its economy. Cost and income calculations were made based on 2017 prices in the study. Costs of the products to be produced were calculated via the formula $(\mathrm{MAB})=(\mathrm{TB}+\mathrm{FG}+\mathrm{DG}+\mathrm{SG}) \mathrm{x}$ 1.0M. Based on the production base prices of the General Directorate of Forestry for $1 \mathrm{~m}^{3}$ fiber-chip poplar wood, income estimates were made by determining the amount of product varieties obtained from stands at different distances and their estimated sales prices. Then, the economy of the interventions on the trembling poplar stands was revealed by making income and cost comparisons. At the end of the study, it was determined that the goods obtained from the initial spacing maintenances were quality of fiber chip wood, $1 \mathrm{~m}^{3}$ of wood was sold as standing tree with a price of approximately $35 \mathrm{TL}$, the total volume of 4,370 trees stamped in the sample areas was $272.83 \mathrm{~m}^{3}$ and the forest enterprise generated a total net income of 9,549.05 TL from this production. According to these results, it was demonstrated that the interval cares and wood production were suitable in term of business economy and provided an economic return to the business at the trembling poplar stands that have not received any maintenance and just passed the age of frequency and reached first intervals in the Erciyes region. Additionally, the production will contribute to meet the raw material need of the forest products industry, to close the wood supply gap, to create employment and added value, and thus, to the national economy.
\end{abstract}

Keywords: Wood production, Trembling poplar, Cost value, Standing tree sale price, Erciyes Mountain.

\footnotetext{
*Sorumlu Yazar (Corresponding Author): 


\section{Giriş}

Ekonomik, ekolojik ve sosyal açıdan büyük öneme sahip olan ormanlar günümüzde küresel bir nitelik kazanmış olup, ormanların korunması, sürdürülebilir şekilde yönetilmesi ve işletilmesi önem arz etmektedir. Bunun için gerekli silvikültürel müdahaleler zamanında ve tekniğine uygun olarak yapılmalıdır (Güzel vd., 2019).

Türkiye'nin orman varlığı 22,3 milyon ha olup, bunun \%48'i ibreli, \%33'ü yapraklı ve \%19'u ibreli + yapraklı karışımı ormanlardır (OGM, 2015). Türkiye ormanlarının \%50'sinin ekonomik fonksiyonlu planlandığı ve işletildiği gelişen teknoloji ve giderek artan odun hammaddesi talebinin karşılanması açısından halen ithal edilmekte olan odun hammaddesi açığının kapatılması düşünüldüğünde, ekonomik fonksiyonlu ormanların gerek planlanması ve gerekse bakımının yapılması ve işletilmesinde silvikültürel müdahaleler son derece önem taşımaktadır (Güzel vd., 2019).

Türkiye'deki y1llık odun hammaddesi tüketimi toplam 40,7 milyon $\mathrm{m}^{3}$ olup, bunun \%41'i doğal ormanlardan elde edilmektedir. Yıllık ortalama hasılat miktarı koru ormanlarında 15,9 milyon $\mathrm{m}^{3}$, baltalık ormanlarında ise 2,4 milyon $\mathrm{m}^{3}$ olmak üzere toplam 18,3 milyon $\mathrm{m}^{3}$ 'dür (Boydak ve Çalışkan, 2014). 2020 yılındaki odun hammaddesi tüketiminin 48,7 milyon $\mathrm{m}^{3}$ olacağı belirtilmektedir (Birler, 1995).

Orman Genel Müdürlüğünün endüstriyel odun üretimi 21,7 milyon $\mathrm{m}^{3}$ olmuştur. Endüstriyel odun talebinin yaklaşık 16,6 milyon $\mathrm{m}^{3}$ 'ü devlet ormanlarından, 3,4 milyon $\mathrm{m}^{3}$ 'ü özel sektör kavak üretiminden karşılanmakta, talebin geriye kalan kısmı (yaklaşık 1,7 milyon $\mathrm{m}^{3}$ ) ithal edilmektedir. Odun hammaddesi ithalatının giderek zorlaşması ve gelecekte ithal imkanlarının azalacağı göz önüne alınarak Orman Genel Müdürlüğünce üretimin hem kalite hem de kantite olarak arttırılmasına yönelik tedbirler alınmalıdır. Bu anlamda baltalıkların koruya tahvili, orman yönetim (amenajman) planlarında daha yeni teknikler ve uygulamalar, bozuk ormanların imar ve ihyası, orman bakımlarına ağırlık verilmesi, kalite üretimi için ağaç budaması sayılabilir (OGM, 2016).

Ülkemizde çok geniş alanlarda titrek kavak (Populus tiremula L.) ormanları mevcuttur. Bir 1ş1k ağacı olan titrek kavă̆ın öncü tür olması, donlara karşı dayanıklı ve ekstrem yetişme ortamı koşullarına uyum göstermesi, boş alanlara gelmesine ve öncü ormanlar oluşturmasına neden olmaktadır. Özellikle Erzurum ve Kayseri Orman Bölge Müdürlüğü başta olmak üzere geniş alanlarda gerek saf gerekse diğer orman ağacı türleri ile karışık titrek kavak ormanlarının varlığı orman amenajman planlarında da gösterilmektedir. Zira mevcut orman amenajman planlarına göre Kayseri Erciyes Dağı eteklerinde $a b, b$ ve $b c$ çağında saf, doğal, tek tabakalı, sık ve hiç bakım görmemiş, sıklık çağını henüz geçmiş ve ilk aralama çağına ulaşmış değişik meşcere tiplerinde yaklaşık 1.468 ha titrek kavak meşceresi bulunmaktadır. Bu çalışma kapsamında yapılan ön etütlere göre bu meşcerelerin bir kısmının üretime konu olabileceği ve silvikültürel açıdan ilk aralama bakımına ihtiyaç oldukları saptanmıştır. Yapılacak ilk aralama müdahaleleri kapsamında odun üretiminin ekonomik açıdan incelenmesi kıt kaynakların etkin kullanılmasına hizmet edecektir. Bu nedenle ilk aralama çalışmalarının ekonomik olup olmadığının araştırılması gerekmektedir.

Meşcere bakım tedbirlerinden biri olan aralamaların hasta ve kötü şekilli bireyleri çıkarmak, meşcereleri tehlikelere karşı dayanıklı hale getirmek, doğal gençleştirmeye hazırlamak ve ara hasılat almak gibi faydaları vardır. Ayrıca aralamaların, son hasılatın kalitesine ve özelliklerine olumlu etkileri söz konusudur. Gerçekten de aralamalar sonucunda son hasılatın kalitesi artmakta, dolayısıyla ürünün pazardaki fiyatı ve üretimin değeri daha yüksek olmaktadır. Ayrıca aralama yapılamamış meşcerelerde son hasılat ince çaplı olacağından, ölçek ekonomisi gereğince birim başına düşen hasat masrafları artmaktadır. Dolayısıyla, aralamaların son hasat masraflarını azaltıcı etkisi de vardır. Özellikle aralamaların şekli, zamanı ve şiddeti işletmenin nakit akışları üzerinde etkili olmaktadır (Daşdemir, 2018).

Değişik ağaç türlerinde aralamaların meşcerelerin genel hacim artımları üzerindeki etkisi konusunda çeşitli hasılat araştırmalar (Wiedemann, 1955; Assmann, 1961; Mitscherlich, 1970; Kalıpsız, 1982; Ceylan, 1986; Eler, 1988, IUFRO, 1990) ve aralamaların şekli, zamanı ve şiddetinin işletmenin nakit akışlarına etkisini ve işletme ekonomisi bakımından inceleyen bazı araştırmalar (Görücü, 1995; Daşdemir ve Güler, 2001) yapılmasına rağmen, Erciyes Dağı eteklerinde yer alan titrek kavak meşcerelerinde silvikültürel müdahalelerin (aralamaların) ekonomisi üzerine herhangi bir çalışma yapılmamıştır. Bu meşcerelerin gerekli bakım tedbirleri ile verimli hale getirilmesi, ara hasılat alınması ve en önemlisi de bu ormanların göreceği fonksiyon itibarıyla devamlılıklarını sağlanmasının araştırılması gerekmektedir. Sahada, ilgili orman işletme müdürlüğü teknik elemanlarınca titrek kavak ormanlarında yapılan silvikültür tatbikatlarında, bakım müdahalelerine yönelik kesimler $400 \mathrm{~m}^{2}$ 'lik örnek alanlarda alçak aralama uygulaması şeklinde yapılmıştır. Ancak bu müdahalelerin ekonomik açıdan sürdürülebilir olup olmadığı bilinmemektedir. Bu nedenle çalışma alanında örnek alanlar alınarak deneme deseni oluşturulması ve silvikültürel müdahalelerin ekonomik sonuçlarının ortaya konması 
gerekmektedir. Bu kapsamda ele alınan bu çalışmanın amacı, Erciyes yöresindeki titrek kavak meşcerelerine yapılacak ilk aralama müdahalelerini odun üretimi açısından incelemek ve ekonomisini ortaya koymaktır. Böylece titrek kavak ormanlarının sürdürülebilir yönetimi sağlanmış olacaktır.

\section{Materyal ve Yöntem}

\section{Materyal}

Kayseri ilindeki titrek kavak meşcereleri, Kayseri Orman İşletme Müdürlüğüne bağlı Kayseri Orman İşletme Şefliğinde 814 ha ve Develi Orman İşletme Şefliğinde 654 ha olmak üzere toplam 1.468 ha'dır. Gölgeli ve güneşli bakılarda yer alan titrek kavak meşcerelerinin tamamı III. bonitet sahalar olup, Kva3-Kvab3-KvMtab3KvMzab3 meşcere tiplerinden oluşmaktadır (KOİM, 2018). Bu çalışma Erciyes Dağında, Kayseri Orman İşletme Şefliği sınırları içinde 1394-2407 m rakımlar arasında yayılıș gösteren doğal, bakım görmemiş, aynı yaşlı, saf ve tek tabakalı titrek kavak meşcerelerinde yürütülmüştür (Şekil 1)

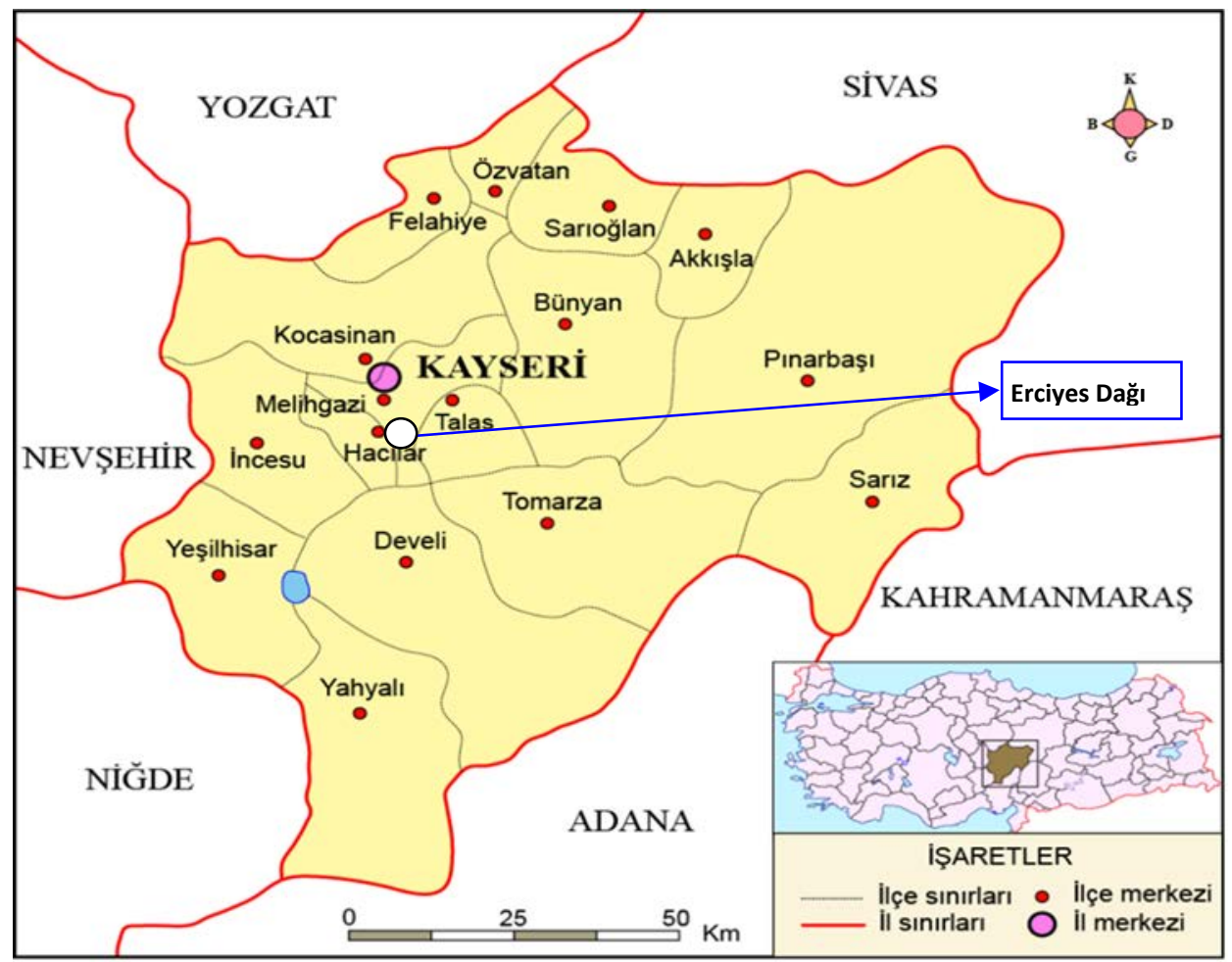

Şekil 1. Kayseri il haritası ve çalışma alanı (URL-1, 2019).

Kayseri Orman İşletme Şefliği titrek kavak meşcerelerinde, ana yola üç farklı mesafede bulunan ve her biri $4.000 \mathrm{~m}^{2}$ olan üç adet deneme alanı alınmış ve 87 deneme ağacı kesilmiştir. Deneme ağaçlarından elde edilebilecek ürün çeşitleri itibariyle emval tespit edilmiş ve hacimlendirilmiştir. Daha sonra, üç farklı deneme alanında ilk aralama bakımı kesimleri yapılmıștır. Bakım yapılan alanlarda toplamda 4.370 ağaç işaretlenmiş ve dikili ağaç tutanakları tanzim edilmiştir. 4.370 adet ağacın hacmi 272,83 $\mathrm{m}^{3}$ olarak hesaplanmıştır. Bakım yapılan alanların sürütme mesafeleri ayrı ayrı hesaplanmış, üç alanın ortalaması alınarak $150 \mathrm{~m}$ olarak sürütme mesafesi tespit edilmiştir.

Fiili masraflar ile tevzii (dağıtım) masrafların hesaplanmasında 2017 yılı birim fiyatları baz alınarak, Orman Genel Müdürlüğünün 288 nolu tamiminden faydalanılmıştır (OGM, 1996). İşletmenin düzenlediği 2017 y1lı kavak dikili ağaç satış tutanaklarındaki hacim, verim yüzdesi, ürün çeşitleri, kesme, sürütme ve taşımaya ilişkin birim fiyatlar ile dikili satış ağaç satış maliyeti ve muhammen bedeli değerleri bu araştırmada materyal olarak kullanılmış ve işletme ekonomisi bakımından değerlendirilmiştir.

\section{Yöntem}

Orman Genel Müdürlüğü (OGM) 1996 yılından itibaren dikili ağaç satışlarını gündeme alarak, normal 
üretimden farklı, alternatif bir üretim ve pazarlama biçimi geliştirmeye çalışmıştır (Daşdemir, 2011). Halen 6877 sayılı "Dikili Ağaç Satışı Tamimi” ile belirli bölgelerde ve türlerde dikili ağaç satışı uygulamalarına devam etmektedir. Üretim işleri ister orman işletmesi tarafından orman köylülerine yaptırılsın, isterse dikili ağaç satışı halinde yaptırılsın, her iki halde de üretim Maliyet Bedeli (MAB) ve Muhammen Satış Bedeli (MUB) Devlet Orman İşletmesi ve Döner Sermayesi Yönetmeliğinin (DSY) 16. maddesine göre hesaplanmaktadır (OGM, 1985). Bu çalışmada da DSY Yönetmeliği dikkate alınarak maliyet ve gelir hesapları aşağıdaki gibi yapılmıştır:

1. Maliyet Hesapları: Çalışmada titrek kavak meşcerelerinde yapılacak üretimim dikili ağaç satışı seklinde uygulandığ 1 belirlenmiştir. Öncelikle titrek kavak meşcereler için düzenlenen Deneme A ğacl ve Verim Tespit Tutană̆ından yararlanılarak örnek alanlardaki meşcerelerden elde edilecek emvalin miktarı tespit edilmiştir. 2017 yılı itibariyle OGM'nin üretim birim fiyatları esas alınarak $1 \mathrm{~m}^{3}$ kavak odunu için fiili giderler hesaplanmıştır. Bunun için Kayseri Orman İşletme Müdürlüğünün 2017 kesme, sürütme ve taşıma birim fiyat kararlarından yararlanılmıştır. Tarife bedeli, dağıtım giderleri ve satış gideri bedelleri OGM'nin 2017 yılında Uygulanacak Tarife Bedeli ve Tevzii Masraf Cetvellerinden alınmıştır (OGM, 2017). Böylece $1 \mathrm{~m}^{3}$ için Maliyet Bedeli (MAB) değeri aşağıdaki formüle göre bulunmuştur (Daşdemir, 2003, 2008);

$\mathrm{MAB}=(\mathrm{TB}+\mathrm{FG}+\mathrm{DG}+\mathrm{SG}) \times 1,0 \mathrm{M}$

Burada; TB: Tarife Bedelini (TL/m³), FG: Fiili Giderleri (kesme + sürütme + taşıma giderleri) $\left(\mathrm{TL} / \mathrm{m}^{3}\right), \mathrm{DG}$ : Dağıtım (tevzii) Giderlerini (genel yönetim giderleri + araştırma ve geliştirme giderleri) (TL/m³), SG: Pazarlama ve Satış Giderlerini $\left(\mathrm{TL} / \mathrm{m}^{3}\right)$ ve M: Orman İmar Giderlerini (\%3) göstermektedir.

MAB hesaplandıktan sonra Muhammen Satış Bedeli (MUB) belirlenmektedir. Bunun için DSY’nin 16. maddesine göre depoların tüketim merkezlerine uzaklığı, pazarın gerekleri ve malların özellikleri dikkate alınarak, MAB üzerinden bir kez olmak üzere orman işletme müdürlüklerince (İ) en çok $\pm \% 20$ ve orman bölge müdürlüğünce (B) en çok $\pm \% 50$ değişiklik yapılarak MUB tespit edilmektedir. Yani MUB'un belirlenmesi aşağıdaki formüle uygun yapılmaktadır (Daşdemir, 2003, 2018);

$\mathrm{MUB}=\mathrm{MAB}+(\mathrm{MAB} \times \pm \% 20 \mathrm{I})+(\mathrm{MAB} \times \pm \% 50 \mathrm{~B})$

MUB orman ürünlerinin satışında kabul edilen en düşük fiyattır. Açık artırmalı satışlarda, açık artırma MUB ile başlamaktadır.

2. Gelir Hesapları: Titrek kavak meşcerelerinde yapılacak bakım çalışmalarının üretim işlerini orman işletmesi tarafından orman köylüsüne yaptırması halinde aşağıdaki gibi bir Net Gelir (NG) hesaplaması söz konusudur;

$$
\sum_{1}^{n} \begin{aligned}
& \text { ÇG }=(\text { Ürürinn Çeşidinin Miktarı) }
\end{aligned}
$$

Ancak dikili ağaç satışlarında ise MAB’a dayanılarak tespit edilen MUB değeri, işletmenin doğrudan $1 \mathrm{~m}^{3}$ için elde edeceği net gelirini oluşturmaktadır. Dolayısıyla dikili satışlarda işletmenin elde edeceği Toplam Net Gelir (TNG); 2 nolu formüldeki gibi hesaplanan muhammen satış bedelinin, üretim miktarıyla çarpılması suretiyle bulunmuştur.

TNG $=$ MUB $\times$ Üretim Miktar1

\section{Bulgular ve Tartışma}

\section{Verim Yüzdesinin Tayini}

Kayseri Orman İşletme Müdürlüğü, Merkez Orman İşletme Şefliği titrek kavak ormanlarında Kva3-Kvab3KvMtab3-KvMzab3 meşcere tiplerinden (Şekil 2) ana yola üç farklı mesafeden, üç farklı deneme alanı alınmış, 87 deneme ağacı işaretlenmiş ve $5,457 \mathrm{~m}^{3}$ emval elde edilebileceği tespit edilmiştir. Sahanın ilk aralama bakımına konu olması nedeniyle deneme ağaçlarının tamamından sadece lif yonga odunu üretmenin mümkün olacağı anlaşılmıştır. Verim yüzdesinin tayini deneme ağacı ve verim yüzdesi tespit tutanağına dayanarak yapılmıştır (Tablo 1). 


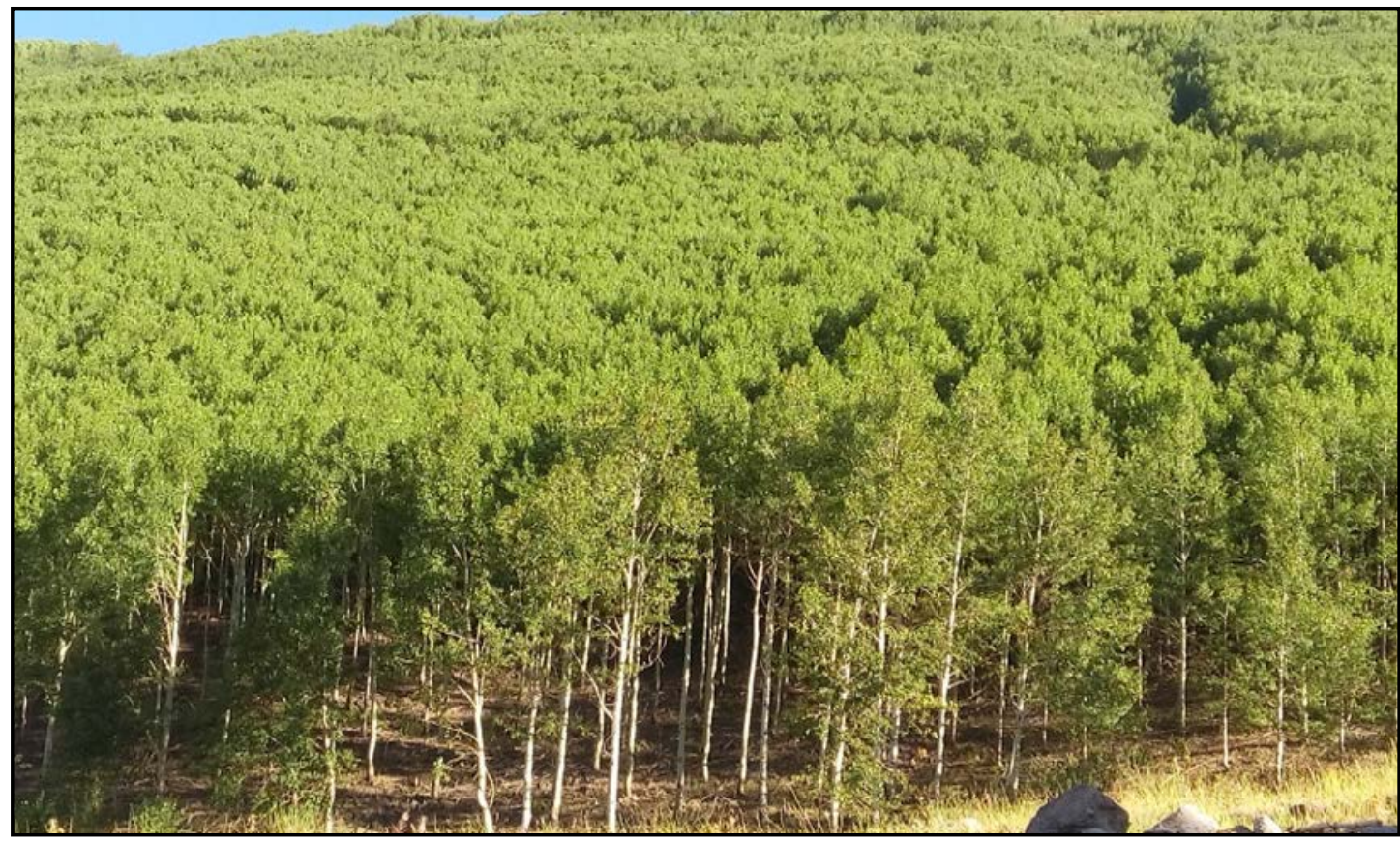

Şekil 2. Erciyes yöresi titrek kavak meşcerelerinin genel görünümü.

Tablo 1. Deneme ağacı ve verim yüzdesinin tespiti.

\begin{tabular}{|c|c|c|c|c|c|}
\hline $\begin{array}{l}\text { Kesilen Deneme Ağacı Adedi } \\
\text { Kesilen Deneme Ağaçları Hacmi } \\
\text { Toplam Ağaç Sayısı } \\
\text { DKGH }\end{array}$ & \multicolumn{5}{|c|}{$\begin{array}{l}87 \text { Adet } \\
5,475 \mathrm{~m}^{3} \\
4.370 \text { Adet } \\
272,83 \mathrm{~m}^{3}\end{array}$} \\
\hline \multicolumn{6}{|l|}{ A-Deneme Ağacı Tespiti } \\
\hline Çap Kademesi (cm) & $\begin{array}{l}\text { DKGH } \\
\left(\mathrm{m}^{3}\right)\end{array}$ & $\begin{array}{c}\text { Toplam } \\
\text { Hacimdeki } \\
(\%) \\
\end{array}$ & $\begin{array}{c}\text { Deneme } \\
\text { Ağacı Hacmi } \\
\left(\mathrm{m}^{3}\right) \\
\end{array}$ & $\begin{array}{l}\text { Bir Ağacın } \\
\text { DKGH }\left(\mathrm{m}^{3}\right)\end{array}$ & $\begin{array}{l}\text { Deneme Ağac1 } \\
\text { Sayıs1 }\end{array}$ \\
\hline Kavak & 130,50 & 47,83 & 2,610 & 0,045 & 58 \\
\hline $12-15,9$ & 117,00 & 42,88 & 2,340 & 0,090 & 26 \\
\hline $16-19,9$ & 25,33 & 9,28 & 0,507 & 0,149 & 3 \\
\hline Toplam & 272,83 & 100 & 5,457 & & 87 \\
\hline \multicolumn{6}{|c|}{ B-Verim Yüzdesine Göre Üretim Miktarı } \\
\hline \multirow{2}{*}{ Elde Edilen Ürün Cinsi ve Nevi } & \multicolumn{3}{|c|}{ Elde Edilen Ürünlerin } & \multirow{2}{*}{\multicolumn{2}{|c|}{$\begin{array}{l}\text { Üretilmesi Öngörülen Toplam Ürün } \\
\text { Miktarı }\left(\mathrm{m}^{3}\right)\end{array}$}} \\
\hline & Hacm & & Verim \%'si & & \\
\hline Yapraklı Lif Yonga Odunu & \multicolumn{2}{|c|}{272,83} & 70 & \multicolumn{2}{|c|}{190,981} \\
\hline
\end{tabular}

Sahada, üç farklı deneme alanında ilk aralama bakımı kesimleri yapılmıştır. Bakım yapılan toplam 1,2 ha alanda (3 denme alanı $\times 4.000 \mathrm{~m}^{2}$ ) 4.370 ağaç işaretlenmiş ve dikili ağaç tutanakları tanzim edilmiştir. 4.370 adet ağacın dikili hacmi 272,83 $\mathrm{m}^{3}$ olarak hesaplanmıştır. Deneme ağaçlarının kesim ve boylanması sonucunda, verim yüzdesi \%70 olarak tespit edilmiştir. \%70 verim yüzdesine göre 272,83 $\mathrm{m}^{3}$ dikili ağaçtan 190,981 $\mathrm{m}^{3}$ lif yonga odunu elde edilebileceği hesaplanmıştır.

\section{Kesme ve Tomruklama Birim Fiyatlarının Hesabı}

Arazide bakım yapılan alanların sürütme mesafeleri ayrı ayrı hesaplanmış, üç alanın ortalaması alınarak, $150 \mathrm{~m}$ olarak sürütme mesafesi tespit edilmiştir. Üretim giderlerinin tespitinde Orman Genel Müdürlüğünün 288 nolu tamiminden faydalanılmıştır. OGM'nin 2017 yılı taban fiyatları baz alınarak kesme ve tomruklama birim fiyatı hesaplanmıştır (Tablo 2). 
Tablo 2. Kesme ve tomruklama birim fiyatının hesaplanması.

\begin{tabular}{|c|c|c|c|c|c|c|c|}
\hline \multicolumn{8}{|c|}{ Kesme ve Tomruklama Birim Fiyat Kararı (Karar Tarihi: 06 Eylül 2017, No: 1) } \\
\hline \multicolumn{2}{|r|}{ Birim Fiyatları (TL) } & \multicolumn{3}{|c|}{ 1. Dönem: 1.1.2019-30.6.2019 } & \multicolumn{3}{|c|}{ 2. Dönem: 1.7.2019-31.12.2019 } \\
\hline $\begin{array}{l}\text { Ağaç } \\
\text { Adı }\end{array}$ & Ürün Çeşitleri $\left(\mathrm{m}^{3}\right)$ & $\begin{array}{c}\text { 1.Dönem } \\
\text { Vahidi } \\
\text { Fiyat }\end{array}$ & $\begin{array}{l}\text { 1.Dönem } \\
\text { Erken } \\
\text { Üretim }\end{array}$ & $\begin{array}{c}\text { 1.Dönem } \\
\text { Kar Özeti } \\
\text { Fiyat }\end{array}$ & $\begin{array}{c}\text { 2.Dönem } \\
\text { Vahidi Fiyat }\end{array}$ & $\begin{array}{l}\text { 2.Dönem } \\
\text { Erken } \\
\text { Üretim }\end{array}$ & $\begin{array}{c}\text { 2.Dönem } \\
\text { Kar Özeti } \\
\text { Fiyat }\end{array}$ \\
\hline Kavak & Tomruk (1,5-4,99 m) & & & & 39,79 & 47,75 & 63,66 \\
\hline Kavak & Tomruk $(\geq 5 \mathrm{~m})$ & & & & 39,79 & 47,75 & 63,66 \\
\hline Kavak & Tel Direği (1,5-8 m) & & & & 51,73 & 59,69 & 75,60 \\
\hline Kavak & Tel Direği ( $\geq 12 \mathrm{~m})$ & & & & 59,69 & 67,65 & 83,56 \\
\hline Kavak & Tel Direği (9-11 m) & & & & 55,71 & 63,67 & 79,58 \\
\hline Kavak & Maden Direği & & & & 45,76 & 53,72 & 69,63 \\
\hline Kavak & Sanayi Odunu & & & & 39,79 & 47,75 & 63,66 \\
\hline Kavak & Kağgtlık Odun & & & & 39,79 & 47,75 & 63,66 \\
\hline Kavak & Kabuklu Kağıtlık Odun & & & & 27,85 & 0 & 0 \\
\hline Kavak & Lif Yonga Odunu & & & & 25,86 & 0 & 0 \\
\hline
\end{tabular}

\section{Sürütme Birim Fiyatının Hesabı}

Yine OGM’nin 288 sayılı tebliği esas alınarak sürütme işine ait standart zaman hesabı yapılmış, İBM (İşçi Birim Maliyeti) ile HBM (Hayvan Birim Maliyeti) ve 2017 yılı için taban fiyatlar baz alınarak Sürütme Vahidi Fiyatı tespit edilmiştir (Tablo 3).

Tablo 3. Sürütme birim fiyatının hesaplanması.

\begin{tabular}{|c|c|c|c|c|c|c|c|}
\hline \multicolumn{8}{|c|}{ Sürütme (Orman İçi İstif Yerine Taşıma) Birim Fiyat Kararı (Karar Tarihi: 06 Eylül 2017, No: 1) } \\
\hline \multicolumn{2}{|c|}{ Birim Fiyatları } & \multicolumn{3}{|c|}{ 1. Dönem: 1.1.2019-30.6.2019 } & \multicolumn{3}{|c|}{ 2. Dönem: 1.7.2019-31.12.2019 } \\
\hline $\begin{array}{l}\text { Ağaç } \\
\text { Ad1 }\end{array}$ & Ürün Çeşitleri $\left(\mathrm{m}^{3}\right)$ & $\begin{array}{c}\text { 1.Dönem } \\
\text { Vahidi } \\
\text { Fiyat } \\
\end{array}$ & $\begin{array}{c}\text { 1.Dönem } \\
\text { Erken } \\
\text { Üretim } \\
\end{array}$ & $\begin{array}{c}\text { 1.Dönem } \\
\text { Kar Özeti } \\
\text { Fiyatı } \\
\end{array}$ & $\begin{array}{l}\text { 2.Dönem } \\
\text { Vahidi Fiyat }\end{array}$ & $\begin{array}{c}\text { 2.Dönem } \\
\text { Erken } \\
\text { Üretim } \\
\end{array}$ & $\begin{array}{l}\text { 2. Dönem } \\
\text { Kar Özeti } \\
\text { Fiyat }\end{array}$ \\
\hline Kavak & Tomruk $(1,5-4,99 \mathrm{~m})$ & & & & 14,36 & 17,23 & 27,28 \\
\hline Kavak & Tomruk $(\geq 5 \mathrm{~m})$ & & & & 16,51 & 19,38 & 29,43 \\
\hline Kavak & Tel Direği (1,5-8 m) & & & & 18,76 & 21,54 & 31,59 \\
\hline Kavak & Tel Direği $(\geq 12 \mathrm{~m})$ & & & & 21,54 & 24,41 & 34,46 \\
\hline Kavak & Tel Direği (9-11 m) & & & & 20,10 & 22,97 & 33,02 \\
\hline Kavak & Maden Direği & & & & 15,80 & 18,67 & 28,72 \\
\hline Kavak & Sanayi Odunu & & & & 14,36 & 17,23 & 27,28 \\
\hline Kavak & Kağıtlık Odun & & & & 14,36 & 17,23 & 27,28 \\
\hline Kavak & Kabuklu Kağıtlık Odun & & & & 10,05 & 0 & 0 \\
\hline Kavak & Lif Yonga Odunu & & & & 9,33 & 0 & 0 \\
\hline
\end{tabular}

\section{Taşıma Birim Fiyatının Hesabı}

Üretimden elde edilen emvalin kesme-boylama-sürütme-rampaya taşıma işinden sonra (Şekil 3), emvalin Yahyalı Orman Deposuna taşınması için yol mesafesi hesaplanmış ve $72 \mathrm{~km}$ olarak tespit edilmiştir. Taşıma işine ait yükleme ve kamyonla taşıma işi için İBM ve KÇZ (Kamyon Çalışma Zamanı) hesaplanmış ve OGM’nin 2017 yılı için taban fiyatlar baz alınarak Kamyon veya Motorlu Araçlarla Yükleme ve Taşıma Vahidi Fiyatı tespit edilmiştir (Tablo 4). 


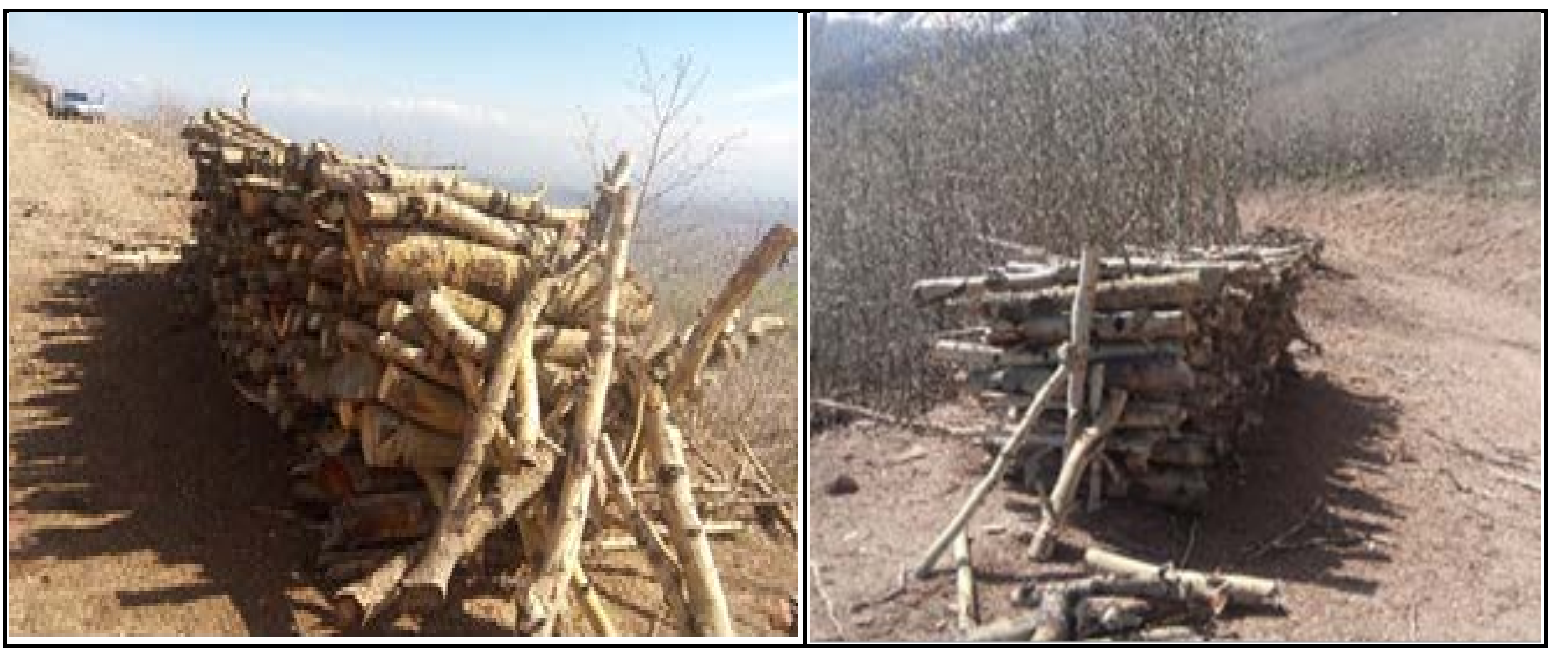

Şekil 3. Rampaya taşınmış kavak lif yonga odunları.

Tablo 4. Taşıma birim fiyatının hesaplanması.

\begin{tabular}{|c|c|c|c|c|c|}
\hline \multicolumn{6}{|c|}{$\begin{array}{l}\text { Kamyon veya Motorlu Araçlarla Yükleme ve Taşıma (Satış İstif Yerlerine Taşıma) } \\
\text { Birim Fiyat Kararı (Karar Tarihi: } 06 \text { Eylül 2017, No: 1) }\end{array}$} \\
\hline \multicolumn{2}{|c|}{ Birim Fiyatları } & \multicolumn{2}{|c|}{ 1.1.2019-30.6.2019 } & \multicolumn{2}{|c|}{ 1.7.2019-31.12.2019 } \\
\hline $\begin{array}{l}\text { Ağaç } \\
\text { Ad1 }\end{array}$ & Ürün Çeşitleri $\left(\mathrm{m}^{3}\right)$ & $\begin{array}{c}\text { 1.Dönem } \\
\text { Taşıma Fiyatı }\end{array}$ & $\begin{array}{c}\text { 1.Dönem Erken } \\
\text { Taşıma Fiyatı }\end{array}$ & $\begin{array}{c}\text { 2.Dönem } \\
\text { Taşıma Fiyat }\end{array}$ & $\begin{array}{c}\text { 2.Dönem Erken } \\
\text { Taşıma Fiyatı }\end{array}$ \\
\hline Kavak & Tomruk $(1,5-4,99 \mathrm{~m})$ & & & 38,88 & 46,79 \\
\hline Kavak & Tomruk $(\geq 5 \mathrm{~m})$ & & & 42,89 & 50,69 \\
\hline Kavak & Tel Direği (1,5-8 m) & & & 50,69 & 58,49 \\
\hline Kavak & Tel Direği ( $\geq 12 \mathrm{~m})$ & & & 58,49 & 66,29 \\
\hline Kavak & Tel Direği (9-11 m) & & & 54,59 & 62,39 \\
\hline Kavak & Maden Direği & & & 38,99 & 46,79 \\
\hline Kavak & Sanayi Odunu & & & 38,99 & 46,79 \\
\hline Kavak & Kağıtlık Odun & & & 38,99 & 46,79 \\
\hline Kavak & Kabuklu Kağıtlık Odun & & & 17,55 & 0 \\
\hline Kavak & Lif Yonga Odunu & & & 17,55 & 0 \\
\hline
\end{tabular}

\section{Fiili Üretim ve Tevzii Masraf Bulguları}

Kayseri Orman İşletme Şefliğinde sıklık çağını henüz geçmiş ve ilk aralama çağına ulaşmış titrek kavak meşcerelerinde yapılacak ilk aralama bakımları neticesinde elde edilecek $1 \mathrm{~m}^{3}$ lif yonga odununun, OGM'nin 2017 yılı birim fiyatları ile Kesme, Sürütme ve Yükleme-Motorlu araçla Yahyalı Orman Deposuna taşıma işleri ve \%10 istihkak fazlası toplamı, yani fiili üretim masrafları Tablo 5'de verilmiştir. Titrek kavak Dikili Ağaç Satışı Maliyet ve Muhammen Bedel Tespit Tutanağı incelediğinde fiili üretim masrafları ile tevzii masraflarının birlikte ve tek kalem halinde hesaplandığ 1 anlaşılmıştır.

Tablo 5. Kavak lif yonga odunu için fiili üretim ve tevzii masraflar toplamı.

\begin{tabular}{lc}
\hline İşlem & Birim Fiyat $\left.\mathbf{( T L} / \mathbf{m}^{\mathbf{3}}\right)$ \\
\hline Kesme-boylama & 25,86 \\
Sürütme-orman içi istif yerine taşıma & 9,33 \\
Yükleme ve satış istif yerine taşıma & 17,55 \\
Toplam & 52,74 \\
\%10 İstihkak Fazlası & 5,27 \\
\hline Genel Toplam & 58,67 \\
\hline
\end{tabular}

\section{Muhammen Satış Bedeli Bulguları}

Tablo 5'e göre Kayseri Orman İşletme Müdürlüğü dikili halde satacağ $1 \mathrm{~m}^{3}$ kavak lif yonga odunu için fiili masraf (kesme + sürütme + taşıma) ve tevzii masraf toplamı olarak 58,67 TL hesaplanmıştır. Ancak Deneme Ağacı ve Verim Yüzdesi Tespit Tutanağına (Tablo 1) göre, DKGH'den elde edilecek verim yüzdesi \%70 
olduğu için, bu rakamın \%70’i (41,07 TL) fiili masraf ve tevzii masraf toplamı olarak alınmıştır (Tablo 6). Bunun üzerine $1 \mathrm{~m}^{3}$ kavak lif yonga odunu için OGM'ce belirlenen ve 2017 yılında Uygulanacak Tarife Bedeli ve Tevzii Masraf Cetvellerinden alınan 1 TL Tarife Bedeli, 0,4 TL Satış Masrafi ve 1,36 TL Beklenmeyen Gider eklenmiştir. Böylece $1 \mathrm{~m}^{3}$ kavak lif yonga odunun açık artırmalı dikili satışında uygulanacak Maliyet Bedeli (MAB) toplam 43,83 TL olarak hesaplanmıştır. Dikili Ağaç Muhammen Satış Bedeli ise, Orman Kanunun ve DSY'nin Orman İşletme Müdürlerine ve Orman Bölge Müdürlerine verdiği yetkiye dayanarak, “dikili ăgaçların özel kalite durumu, üretimdeki güçlük kriterleri, tüketim merkezlerine uzaklı̆g, üretilecek emvalin bu tüketim merkezlerine ulaştırmadaki zorluk ve kolaylıklar ile piyasa şartları, son satıs ortalamaları ve maliyet bedeli gibi faktörler dikkate alınarak" $35 \mathrm{TL} / \mathrm{m}^{3}$ olarak tespit edilmiştir. Yani orman teşkilatı yöneticileri maliyet bedeli üzerinden -\%20,15 oranında indirim yaparak, kavak lif yonga odunun açık artırmalı dikili satışında uygulanacak muhammen bedeli bulmuştur.

Tablo 6. Açık artırmalı dikili ağaç satışı maliyet ve muhammen bedel tespit tutanağı.

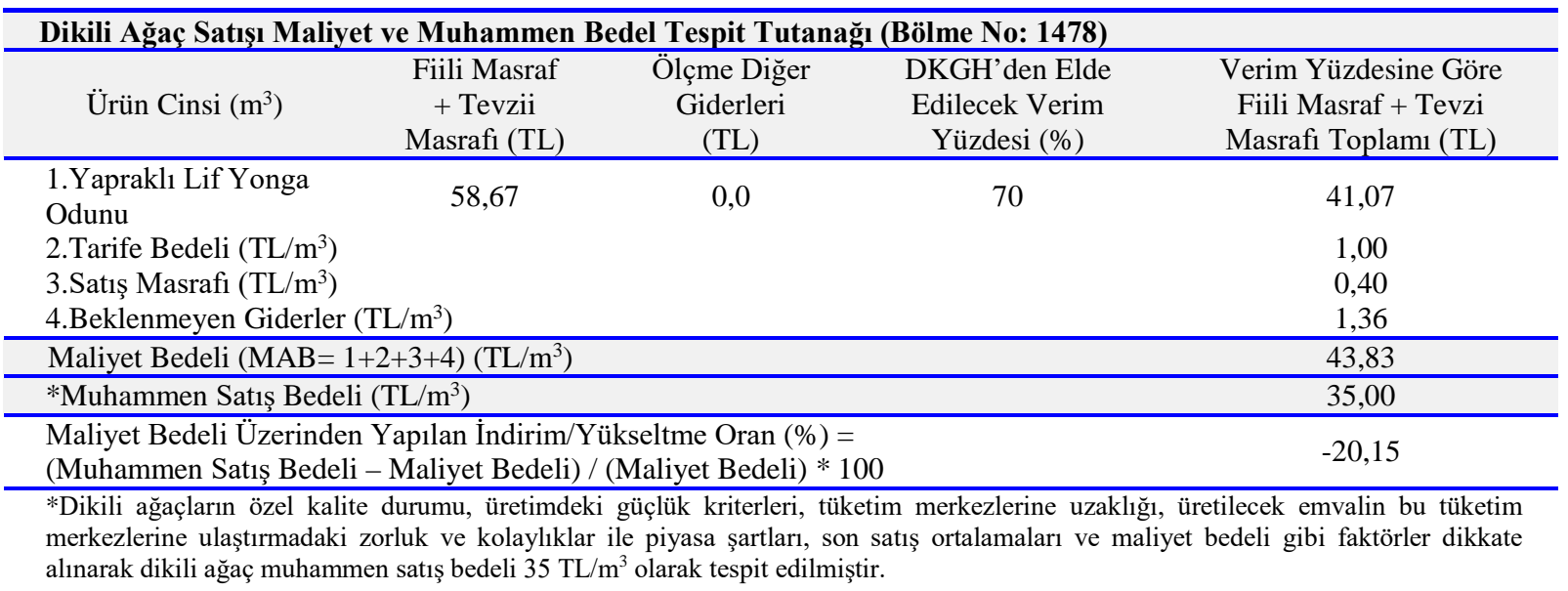

\section{İşetmenin Net Geliri}

Yukarıda elde edilen birim fiyatlar ve bulgular doğrultusunda; üç farklı deneme alanında, toplam 1,2 ha alanda dikili damgası yapılan $272,83 \mathrm{~m}^{3}$ kavak odunun, dikili ağaç olarak satışının yapılması halinde, vergiler hariç, orman işletmesinin elde edeceği toplam net gelir (TNG) miktarı, 2017 yılı fiyatlarıyla;

$\mathrm{TNG}=272,83 \mathrm{~m}^{3} \times 35 \mathrm{TL}=9.549,05 \mathrm{TL}$ olarak bulunmuştur.

Dolayısıyla 1.468 ha'lı titrek kavak meşcerelerinin tamamında ilk aralama bakımlarının yapılması halinde ilgili orman işletmesinin 11.681.671,17 TL $(=1.468 / 1,2 \times 9.549,05)$ net gelir elde edeceği tahmin edilmiştir.

\section{Sonuçlar ve Öneriler}

Bu çalışmada; Erciyes yöresinde yayılış gösteren aynı yaşlı titrek kavak meşcerelerinde yapılacak ilk aralama bakımı çalışmaları işletme ekonomisi yönünden incelenmiştir. Bakım ve üretim işleri dikili ağaç satışı şeklinde gerçekleştirilen titrek kavak meşcerelerinde örnek alanlar alınmıştır. Örnek alanlarda yapılan silvikültürel müdahalelerin neticesinde toplam 4.370 ağacın damgası yapılmış ve çıkarılacak dikili kabuklu gövde hacmi 272,83 $\mathrm{m}^{3}$ hesaplanmıştır. Deneme ağaçlarının kesim ve boylanması neticesinde, verim yüzdesi \%70 olarak tespit edilmiştir. \%70 verim yüzdesi ile $272,83 \mathrm{~m}^{3}$ dikili ağaçtan $190,981 \mathrm{~m}^{3}$ lif yonga ürünü elde edilebileceği saptanmıştır.

OGM'nin 2017 yılı üretim taban fiyatları baz alınarak, $1 \mathrm{~m}^{3}$ lif yonga odununun üretim maliyeti (MAB) yürürlükteki Devlet Orman İşletmesi ve Döner Sermayesi Yönetmeliği hükümlerine göre, MAB $=(\mathrm{TB}+\mathrm{FG}+$ $\mathrm{DG}+\mathrm{SG}) \times 1,0 \mathrm{M}$ formülüyle hesaplanmıştır. Formülde yer alan TB ve SG, OGM tarafından belirlenmiştir. FG hesaplanırken OGM'nin 288 nolu tamimi ve taban fiyatları baz alınarak, dikili satış yapıldığı için DG’nin (tevzii masraflar) ve M’nin (orman imar giderleri) maliyet hesaplara katılmamıştır. Buna göre FG = 41,07 TL, $\mathrm{TB}+\mathrm{SG}=1,40 \mathrm{TL}$ ve Beklenmedik Giderler $=1,36 \mathrm{TL}$ alınarak $\mathrm{MAB}=43,83 \mathrm{TL}$ ve $\mathrm{MUB}=35 \mathrm{TL}$ bulunmuştur. Yani MAB üzerinde işletme yöneticileri -\%20,15 oranında indirime giderek muhammen satıŞ bedelini (MUB) tespit etmiştir. Dolayısıyla açık artırmalı dikili ağaç satışlarında yönetici yetkisi negatif yönde kullanılmıştır. Yönetici yetkisinin pozitif yönde kullanılması işletme gelirlerine olumlu katkı yapacaktır. 
Araştırmada; Erciyes yöresi titrek kavak meşcerelerinde yapılacak ilk aralama bakım çalışmalarından elde edilecek emvalin lif yonga odunu niteliğinde olduğu ve bunun da alıcısın Kastamonu Entegre Ağaç Sanayi olduğu anlaşılmıştır. $1 \mathrm{~m}^{3}$ titrek kavak odunun yaklaşık 35 TL bir bedelle alıcıya dikili ağaç halinde satıldı ̆̆1, böylece 1,2 ha'lık örnek alanlarda damgalanan toplam 4.370 adet ağacın hacminin $272,83 \mathrm{~m}^{3}$ olduğu ve bu kadar hacimden işletmenin 2017 yılı fiyatlarıyla toplam 9.549,05 TL net gelir ede ettiği saptanmıştır. Bakım görmesi gereken 1.468 ha titrek kavak meşceresinin tamamında ilk aralama bakımlarının yapılması halinde, ilgili orman işletmesinin 11.681.671,17 TL net gelir elde edeceği tahmin edilmiştir.

Erciyes yöresinde saf, doğal, tek tabakalı, sık ve hiç bakım görmemiş, sıklık çağını henüz geçmiş ve ilk aralama çağına ulaşmış titrek kavak meşcerelerinin silvikültürel açıdan bakıma ihtiyacı vardır. Ayrıca yapılacak ilk aralama bakımı çalışmaları işletme ekonomisi bakımından incelendiğinde; titrek kavak meşcerelerinde üretimin yapılmasının ve ürün elde edilmesinin uygun olduğu, yapılacak bakım kesimi neticesinde elde edilecek ürünün işletmeye ekonomik bir getiri sağladığı belirlenmiştir. Titrek kavak meşcerelerinin tamamı aynı bonitet sınıfında (III. bonitet) olduğu için amenajman planı verileri dikkate alınarak, işletmenin net gelirini maksimize edecek şekilde ilk aralama bakım çalışmalarına işletmeye en yakın alanlardan (bölmelerden) başlanması gerekmektedir. İşletmeye uzaklıklarına göre bölmelerin bakım müdahalesi sırasının (scheduling) ortaya konulması, kapalılığı fazla kırmadan ve gögüs yüzeyini optimalin altına düşürmeden silvikültür tekniğinin gerekleri doğrultusunda mutedil alçak aralamaların uygulanması gerekmektedir.

Sonuç olarak bakım çalışmalarından elde edilecek ürünler her ne kadar lif yonga odunu niteliğinde olsa bile, titrek kavak meşcerelerine yapılacak ilk aralama çalışmaları orman ürünleri sanayinin ihtiyacı olan hammaddenin karşılanmasına, söz konusu sanayinin gelişmesine, odun arz açığının kapatılmasına, istihdam ve katma değer yaratılmasına neden olacaktır. Diğer yandan kalan meşcerelerin sağlamlığı, hacim artımı, son hasılatın kalitesi, işletmenin gelirleri artacak ve böylece ormanların sürdürülebilir yönetimine ve ülke ekonomisine olumlu katkılar yapılmış olacaktır. Bu nedenle Erciyes yöresi titrek kavak meşcerelerinde bir an önce ilk aralama bakımı çalışmalarının ve dolayısıyla odun hammaddesi üretiminin yapılması gerekmektedir.

\section{Teşekkür}

Bu çalışma, Bartın Üniversitesi, Fen Bilimleri Enstitüsü, Orman Mühendisliği Anabilim Dalında 2019 yılında sonuçlandırılan bir Yüksek Lisans Dönem Projesinden üretilmiştir. Çalışmanın ilk hali 17-19 Eylül 2019 tarihlerinde Kayseri’de düzenlenen “Titrek Kavağın (Populus tremula L.) Biyolojisi, Silvikültürel Özellikleri ile Orman Endüstrisinde Kullanımı” adlı çalıştaya bildiri olarak sunulmuştur.

\section{Kaynaklar}

1. Assmann, E. (1961). Waldertragskunde. BLV Verlagsgesellschaft, München, Bonn-Wien, Germany.

2. Birler, A. S. (1995). Ormanlarımızın Korunması İçin Endüstriyel Plantasyonların Önemi. Tema Vakfı Yayınları No: 8, İstanbul.

3. Boydak, M., Çalışkan, S. (2014). Ağaçlandırma. OGEM-VAK Yayınları, ISBN 978-975-93943-8-7, Ankara.

4. Ceylan, B. (1986). Muğla Yöresindeki Genç Kızılçam Meşcerelerinde İlk Aralama Müdahaleleri Üzerine Silvikültürel Araştırmalar. OAE, Teknik Bülten Yayın No: 196, 102 s., Ankara.

5. Daşdemir, İ. (2003). Asli Orman Ürünlerinde Fiyat Analizi (Zonguldak Orman Bölge Müdürlüğ̈̈ Örneği). ZKÜ Bartın Orman Fakültesi Yayınları, Üniversite Yayın No: 26, Fakülte Yayın No: 12, ISBN 975-713822-7, 119 s., Bartın.

6. Daşdemir, İ. (2011). Dikili Ağaç Satışlarının Uygulanması Üzerine Değerlendirmeler. Bartın Üniversitesi Orman Fakültesi Dergisi, Cilt 13, Sayı 20, s.71-79, Bartın.

7. Daşdemir, İ. (2018). Ormancılık İşletme Ekonomisi (4. Baskı). Bartın Üniversitesi Yayın No: 10, Orman Fakültesi Yayın No: 6, ISBN 978-605-60882-8-5, 407 s., Bartın.

8. Daşdemir, I., Güler, S. (2001). Sarıkamış Karanlıkdere Dr. Ali Topçuoğlu Araştırma Ormanında Silvikültürel Uygulamaların (Aralamaların) Meşcere Kuruluşu Üzerine Etkileri ve Ekonomisi. DA Ormancılık Araştırma Müdürlüğü, Teknik Bülten No: 4, 85 s., Erzurum.

9. Eler, Ü. (1988). Antalya Bölgesi Doğal Kızılçam (Pinus brutia Ten.) Meşcerelerinde Aralama ve Hazırlama Kesimlerinin Artım ve Büyüme Yönünden Etkileri. OAE, Teknik Bülten No: 203, 54 s. Ankara.

10. Görücü, Ö. (1995). Orman İşletmelerinde Üretim Planlamasının Geliştirilmesi Konusunda Araştırmalar. İÜ, Fen Bilimleri Enstitüsü Doktora Tezi, 97 s., İstanbul. 
11. Güzel, A. O., Turna, İ., Koç, F., Kılıç, Y., Akbin, G. (2019). Titrek Kavak (Populus tremula L.) Meşcerelerinde Gecikmiş Aralama Kesimlerinin Meşcere Büyümesi ve Bazı Toprak Özellikleri Üzerine Etkileri (Kayseri Erciyes Dağı Örneği). OGM, İç Anadolu Ormancıllk Araştırma Enstitüsü Müdürlüğünün ANK-23.2153 (2019-2026) nolu Araştırma Projesi, 39 s., Ankara.

12. IUFRO (1990). New Approaches to Spacing and Thinning in Plantation Forestry. FRI Bulletin No: 151, 360 pp., New Zealand.

13. Kalıpsız, A. (1982). Orman Hasılat Bilgisi. İÜ, Orman Fakültesi Yayın No: 328, 349 s., İstanbul.

14. KOİM (2018). Kayseri Orman İşletme Müdürlüğü, Kayseri ve Develi Orman İşletme Şeflikleri Amenajman Planları. Kayseri.

15. Mitscherlich, G. (1970). Wald Wachstum und Umwelt. J.D. Sauerländer's Verlag, Frankfurt, Germany.

16. OGM (1985). Devlet Orman İşletmesi ve Döner Sermayesi Yönetmeliği. Seri No: 21, Sıra No: 653, Ankara.

17. OGM (1996). Asli Orman Ürünlerinin Üretim İşlerine Ait 288 Sayılı Tebliğ. Orman Genel Müdürlüğü Tamimi, 160 sayfa, Ankara.

18. OGM (2015). Türkiye Orman Varlı̆̆l-2015. TC Orman ve Su İşleri Bakanlığı, Orman Genel Müdürlüğü Yayını, 32 s., Ankara.

19. OGM (2016). Oduna Dayalı Orman Ürünlerinin Üretim ve Pazarlama Faaliyetleri. Orman Genel Müdürlüğü İşletme ve Pazarlama Dairesi Başkanlığı Raporu, 73 s., Ankara. https://www.ogm.gov.tr/ekutuphane/EgitimDokumanlari/18.05.2019.

20. OGM (2017). 2017 Yılında Uygulanacak Tarife Bedeli ve Tevzii Masraf Cetvelleri. Orman Genel Müdürlüğü, Ankara.

21. URL-1 (2019). Kayseri Il Haritasl (R. Sayg1l1 2015). https://unalpvc.wordpress.com/ 23.05.2019.

22. Wiedemann, E. (1955). Ertragskundliche und Waldbauliche Grundlagen der Forst-wirtschaft. J.D. Sauerländer's Verlag, Frankfurt, Germany. 